\title{
Does prolonged pneumoperitoneum affect the kidney? Oxidative stress, stereological and electron microscopy study in a rat model
}

Diogo B. de Souza, Waldemar S. Costa, Luiz E. M. Cardoso, Marlene Benchimol, Marco A. PereiraSampaio, Francisco J. B. Sampaio

Urogenital Research Unit, State University of Rio de Janeiro (DBS, WSC, LEMC, MAPS, FJBS); Santa Ursula University (MB) and Department of Morphology, Fluminense Federal University (MAPS), RJ, Brazil

\section{ABSTRACT}

Purpose: Pneumoperitoneum (Pp) at 12 to $15 \mathrm{mmHg}$ in rats is associated with kidney damage. However, $\mathrm{Pp}$ at $8 \mathrm{mmHg}$ is now known to best correlate to working pressures used in humans. Thus the aim of this work was to study the kidney of rats submitted to prolonged $\mathrm{Pp}$ at $8 \mathrm{mmHg}$.

Materials and Methods: Rats were divided into a Sham group ( $\mathrm{n}=14)$, submitted to anesthesia, and a Pp group ( $\mathrm{n}=14$ ), submitted to Pp at $8 \mathrm{mmHg}$, followed by deflation. In both groups, 7 animals were immediately killed and their kidneys were used for oxidative stress analyses. The remaining 7 rats in each group were evaluated after 6 weeks for the number of glomeruli and podocyte morphology.

Results: For all analyzed parameters Sham and Pp groups presented no statistical difference.

Conclusion: When submitted to adequate Pp pressures ( $8 \mathrm{mmHg}$ ), no kidney damage occurs in rats.

\section{ARTICLE INFO}

\section{Key words:}

Pneumoperitoneum; Kidney; Laparoscopy; Oxidative Stress; Morphometry

Int Braz J Urol. 2013; 39: 30-6

Submitted for publication:

March 15, 2012

Accepted after revision:

August 14, 2012

\section{INTRODUCTION}

During laparoscopic surgery in humans, pneumoperitoneum $(\mathrm{Pp})$ has been associated with a transient decrease in renal function. This may be considered an important negative aspect of all laparoscopic surgeries when patients are submitted to abdominal insufflation and mainly during laparoscopic live donor nephrectomy when the quality of the graft collected is of upmost importance for the recipient. In spite of this, long-term clinical consequences have not been observed yet, mainly because renal function usually returns to normal levels after deflation (1).
Several studies conducted in rats showed oxidative stress injury and other histopathological changes in renal tissue. These experiments used intra-abdominal pressures routinely applied in human clinical settings (12 to $15 \mathrm{mmHg}$ ) (2-6). However, recent evidences indicate that Pp above $8 \mathrm{mmHg}$ in rats correspond to much higher pressures than those that are normally used in humans. Therefore, these experimental studies would not simulate laparoscopic working pressures in the clinical setting, and the reported renal damage might be simply a result of an abnormally high Pp pressure (7). 
To address this issue, in the present study we induced in rats a prolonged $8 \mathrm{mmHg} \mathrm{Pp}$ and then investigated the short-term oxidative stress alterations and the long term morphological changes in the kidney applying stereological and electron microscopic methods.

\section{MATERIALS AND METHODS}

\section{Animals}

Twenty-eight Wistar male rats aged 4 to 6 months and weighing 250 to $360 \mathrm{~g}$ were used in this study. The rats were kept in a room with controlled temperature $\left(25 \pm 1^{\circ} \mathrm{C}\right)$ and with an artificial dark-light cycle (lights on from 7:00 am to 7:00 pm). They were fed standard rat food and water ad libitum.

All experiments were performed in accordance with the Brazilian laws for scientific use of animals, and the project was approved by the local ethical committee.

\section{Groups}

The rats were randomly assigned into a Sham group ( $\mathrm{n}=14)$, which was submitted only to anesthesia for 210 minutes, and a Pp group $(\mathrm{n}=14)$, which underwent, under anesthesia, 180 minutes of $\mathrm{Pp}$ at $8 \mathrm{mmHg}$ followed by 30 minutes of deflation. Immediately after these procedures, 7 animals were killed in each group and their kidneys were used for oxidative stress analyses. The remaining 7 rats from each group were killed 6 weeks later and their kidneys were used for stereological and electron microscopy analyses. All analyses were blindly performed.

\section{Pneumoperitoneum}

The animals were anesthetized by intraperitoneal injection of ketamine $(80 \mathrm{mg} / \mathrm{kg}$ body weight) and xylazine (10 mg/kg body weight) with spontaneous breathing during the experiment. In the Pp group, a 21-gauge needle was inserted into the abdominal cavity and a Pp at $8 \mathrm{mmHg}$ was established with $\mathrm{CO}_{2}$ by using an electronic insufflator. After 180 minutes of $\mathrm{Pp}$, the abdominal cavity was deflated, and the animals remained anesthetized for 30 minutes.

\section{Stereological analyses}

The volume of the right kidneys was estimated by the Sherle's method (8); then the kidneys were sectioned frontally, fixed in 10\% formaldehyde and routinely processed for paraffin embedding. Serial $5 \mu \mathrm{m}$ sections of the entire kidney were obtained and stained with hematoxylin and eosin (HE). The cortical-medullar ratio was estimated by using the Cavalieri principle (9) and the absolute cortical volume (CV) was calculated by multiplying the cortical-medullary ratio by the renal volume.

The left kidneys were sectioned in small fragments, fixed in 10\% formaldehyde and routinely processed for obtaining $5 \mu \mathrm{m}$ thickness HE stained slices. From each animal, different randomly sections of the renal cortex were obtained, from which 26 histological fields were captured at a 200x magnification and analyzed. A M42 test-system was applied to obtain the glomerular volume density (Vv[glom]) by the point-counting technique (9). The volume weighted mean glomerular volume (VWGV) was estimated by using the point-sampled intercepts method $(10,11)$ analyzing 50 glomeruli per animal.

The estimation of the total number of glomeruli per kidney was calculated by multiplying the $\mathrm{CV}$ by the $\mathrm{Vv}$ [glom] and dividing the result by the VWGV (12).

\section{Electron microscopy analyses}

Small fragments of the left kidneys from the Sham and Pp groups were used for investigating podocyte effacement. Samples were processed for scanning and transmission electron microscopy as previously described (13). Briefly, the tissue was minced and fixed in 2.5\% glutaraldehyde overnight and post-fixed in 1\% 0s04. For scanning electron microscopy, the fragments were dehydrated in ethanol, critical point-dried with $\mathrm{CO}_{2}$ and sputter-coated with gold-palladium and examined on a JEOL5800 scanning electron microscope. For transmission electron microscopy, the samples were gradually dehydrated in acetone and embedded in Epon. Ultra-thin sections were stained in 5\% uranyl acetate and 1\% lead citrate and then observed on a JEOL1210 transmission electron microscope.

Podocyte effacement was assessed qualitatively by scanning and transmission electron microscopy, and quantitatively by transmission electron microscopy (14). The quantification was 
carried out by measuring the length of foot processes in contact with the basement membrane using the software ImageJ. At least 100 foot processes per animal were used to calculate individual mean.

\section{Oxidative stress analyses}

One fragment of the left kidney was washed with ice-cold $0.1 \mathrm{M}$ phosphate buffer, $\mathrm{pH} 7.4$ and stored at $-20{ }^{\circ} \mathrm{C}$. Then it was homogenized in the same buffer at a concentration of 0.1 (g tissue/ $\mathrm{mL}$ ), centrifuged at $10000 \mathrm{~g}$ at $4{ }^{\circ} \mathrm{C}$ for $15 \mathrm{~min}$. Supernatants were removed and stored at $-200 \mathrm{C}$ until analyses.

Malondialdehyde (MDA), which is formed by lipid peroxidation, was assayed by a colorimetric method using thiobarbituric acid (15). Protein oxidation was assessed by measuring the protein carbonyl content after reacting with dinitrophenylhydrazine (16).

Protein carbonyl (nMol/mg) and MDA (nMol/mg) contents were expressed in relation to tissue protein concentration, which was measured with the Lowry method (17).

\section{Statistical analysis}

Student's-t-test was used for all mean comparisons. For all comparisons $p<0.05$ was considered significant. Analyses were performed using GraphPad Prism software.

\section{RESULTS}

\section{Stereological analyses}

No statistically significant differences in morphometric values were found among the groups studied. The results of the analyses are presented in Table- 1 .

\section{Electron microscopy analyses}

No signs of podocyte effacement were seen in both groups. The foot processes were well preserved in both Sham and Pp groups, displaying the characteristic interdigitating pattern with its neighbouring cells, and leaving in between a normal sized slit diaphragm (Figure-1). This was confirmed by quantitative assessment of the length of the foot process in contact with the basement

Table 1 - Stereological data of kidneys from rats of groups Sham $(n=7)$ and Pneumoperitoneum $(P p)(n=7)$. The Pp group was submitted to $8 \mathrm{mmHg}$ of Pp for 3 hours, while Sham group was submitted only to anesthesia for the same time.

\begin{tabular}{lccc}
\hline & Sham & Pp & P value \\
\hline Kidney mass $(\mathrm{g})$ & $1.4 \pm 0.31$ & $1.3 \pm 0.39$ & 0.561 \\
Kidney mass index $(\mathrm{g} / \mathrm{kg})$ & $3.8 \pm 0.75$ & $3.8 \pm 0.97$ & 0.928 \\
Kidney volume $\left(\mathrm{cm}^{3}\right)$ & $1.6 \pm 0.22$ & $1.6 \pm 0.26$ & 0.924 \\
Kidney volume index $\left(\mathrm{cm}^{3} / \mathrm{kg}\right)$ & $4.3 \pm 0.41$ & $4.4 \pm 0.26$ & 0.385 \\
Cortical/medullar ratio $(\%)$ & $60.9 \pm 6.3$ & $59.3 \pm 2.0$ & 0.537 \\
Cortical Volume $\left(\mathrm{cm}^{3}\right)$ & $1.0 \pm 0.16$ & $0.9 \pm 0.16$ & 0.497 \\
Vv[Glom] $(\%)$ & $6.2 \pm 0.9$ & $6.2 \pm 0.7$ & 0.931 \\
VWGV $\left(10^{4} \mu m^{3}\right)$ & $155.8 \pm 18.8$ & $154.6 \pm 8.3$ & 0.881 \\
Glomeruli per kidney $\left(10^{3}\right)$ & $41.1 \pm 10.1$ & $37.9 \pm 6.8$ & 0.512 \\
Length of foot process $(\mathrm{nm})$ & $327.1 \pm 53$ & $304.7 \pm 40$ & 0.475 \\
\hline
\end{tabular}

Data expressed as mean $\pm \mathrm{SD} ; \mathrm{Vv}[$ Glom], glomerular volume density; VWGV, volume weighted mean glomerular volume. 
membrane, which showed no statistical difference between the two groups (Table-1).

\section{Oxidative stress analyses}

The mean concentrations of MDA and Protein Carbonyl are shown in Figures 2 and 3 respectively. No statistical difference was found between Sham and Pp groups.

\section{DISCUSSION}

Since the beginning of laparoscopy, physiologic alterations induced by Pp have been a concern and as such have been widely studied. However, following the advent of laparoscopic live donor nephrectomy, studies have focused on renal function, especially with regard to graft quality and the preservation of adequate function in the remaining kidney in the live donor (1).

The rat is the most used animal model for studies on $\mathrm{Pp}$, and the most commonly working Pp pressures used in humans (12-15 $\mathrm{mmHg}$ ) are usually applied to this experimental animal. It should be pointed out, however, that when these pressures were used (3-6), there were no data on whether they would induce in the rat the same physiological responses they do in humans. Indeed, it has later been demonstrated (7) that Pp at pressures higher than $8 \mathrm{mmHg}$ in rats does not simulate the usual working pressures employed in humans. Therefore, $8 \mathrm{mmHg}$ was used in the present study based on this recent knowledge on the equivalence of Pp pressures between rats and humans. Also, it was demonstrated that intra-abdominal pressures of $10 \mathrm{mmHg}$ or higher cause severe acidosis in rats (18), suggesting that this species is more sensitive to $\mathrm{Pp}$ than humans. More information is still necessary to better correlate the intra-abdominal pressures between humans and animal models. The present knowledge suggests that $8 \mathrm{mmHg}$ in the rat would correspond to a high working pressure in humans, but the imprecise correlation of pneumoperitoneum between the species is a limitation of this work.

Figure 1 - Electron micrographs of glomeruli showing no difference in podocyte morphology between the sham (A and $B)$ and pneumoperitoneum (C and D) groups. Scanning electron microscopy ( $A$ and $C$ ); Transmission electron microscopy (B and D).
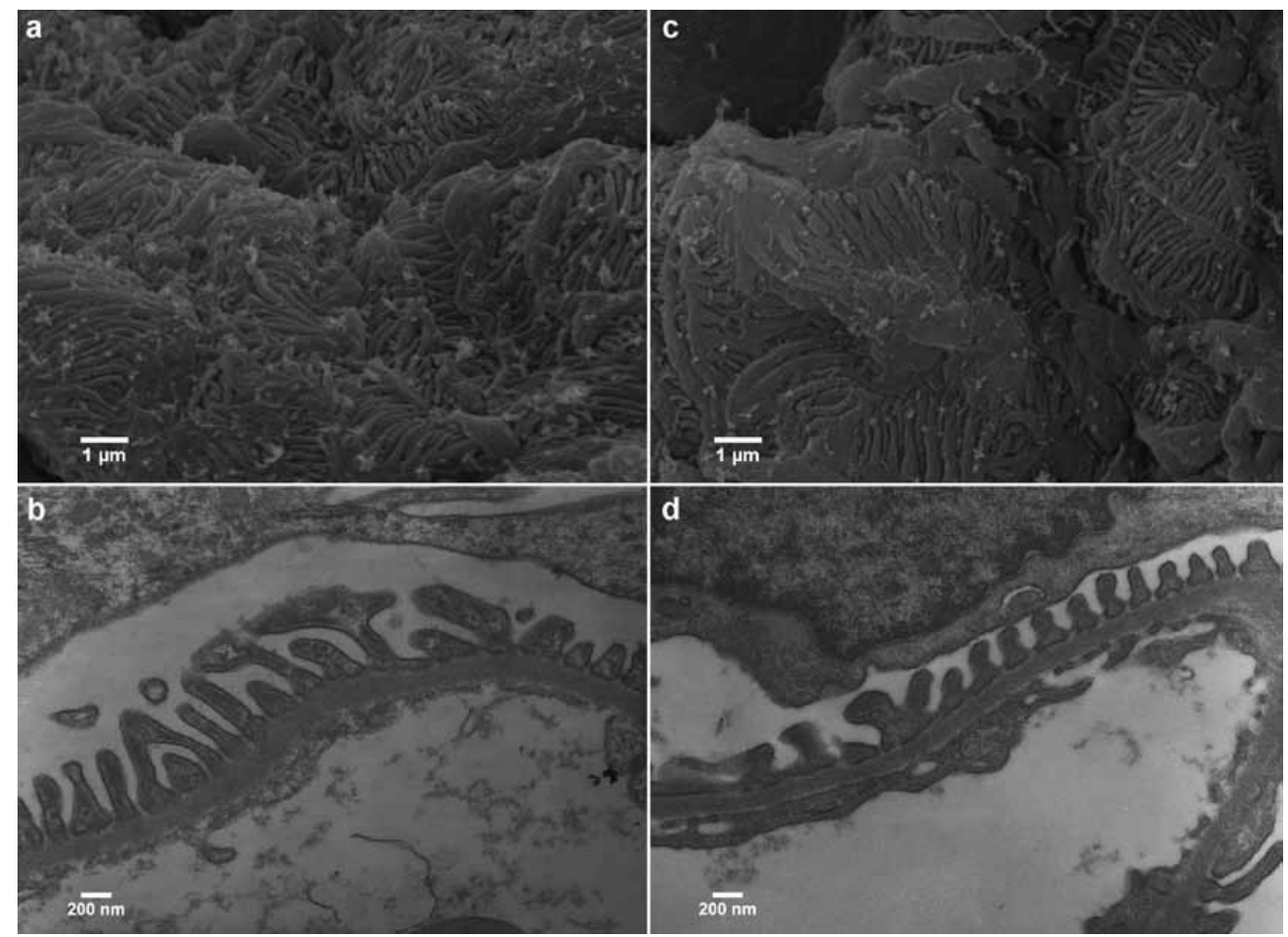
Figure 2 - Malondialdehyde concentration in renal tissue of rats submitted to $8 \mathrm{mmHg}$ pneumoperitoneum for 3 hours. The bars represent men and standard deviation. The means are not significantly different ( $t$ test, $\mathbf{p}=\mathbf{0 . 8 7 1}$ ).

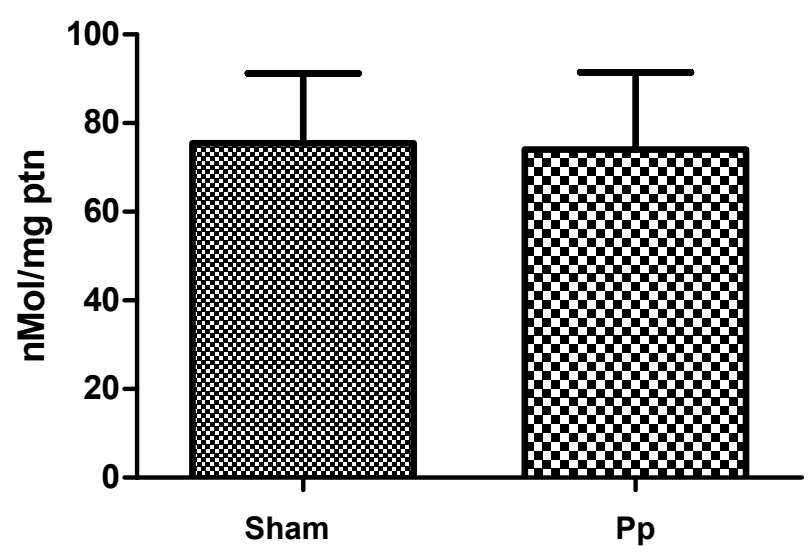

Morphological changes of the rat renal tissue submitted to Pp have been analyzed during the last years, and controversial results were obtained. Although Yilmaz et al. (4) showed renal histological changes in rats submitted to Pp at $15 \mathrm{mmHg}$, other authors reported that 12 and $15 \mathrm{~mm} \mathrm{Hg} \mathrm{Pp} \mathrm{do}$ not result in renal damage in rats $(19,20)$. Also, in studies with a rat model of laparoscopic live donor nephrectomy both donor and recipient kidney specimens did not show any deleterious effects from abdominal insuflattion after two weeks (21) or one year (22). It should be pointed out that these studies employed simple histological observation or histopathological grading systems to evaluate the morphological changes, all of which are affected by subjective interpretations by the observer. This might explain the disparity between the results of different investigators. In contrast, the findings of the present study are based on objective unbiased stereological methods which yield reproducible numerical results and allow more robust statistical comparisons (23).

A recent study showed that there is a positive correlation between the number of apoptotic cells in renal cortex and medulla and the increase of the intraperitoneal pressure and $\mathrm{Pp}$ exposure time in the rat model (24). Even under $8 \mathrm{mmHg}$ pressure, the kidney in an isolated chamber diminishes the urinary output and presents a higher number of apoptotic cells (25). The present study showed
Figure 3 - Protein carbonyl concentration in renal tissue of rats submitted to $8 \mathrm{mmHg}$ pneumoperitoneum for 3 hours. The bars represent men and standard deviation. The means are not significantly different ( $t$ test, $\mathrm{p}=\mathbf{0 . 8 9 3}$ ).

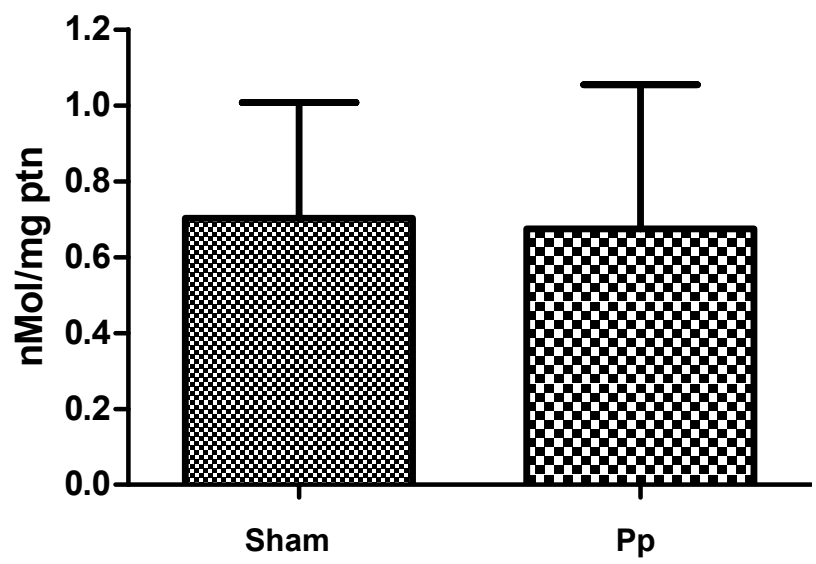

that any alteration, which may be caused by a Pp at $8 \mathrm{mmHg}$, did not affect the number of glomeruli per kidney in rats after long term evaluation, even in a prolonged $\mathrm{Pp}$ model. The apoptotic cells in the previous study (24) can be mostly tubular cells which can heal or be replaced after injury, and by this way, the nephron as a whole can still be preserved.

The present study investigated the morphological aspects of foot processes in the podocytes, which constitute an important component of the glomerular filtration barrier, restricting the transport of proteins and solutes to the urine. Podocyte effacement is associated with loss of slit diaphragm, leading to proteinuria and loss of kidney function. Podocyte effacement is a common event observed in a number of glomerular diseases, including renal ischemia (26).

Some authors proposed that the diminished renal blood flow during Pp and its return to normal flow after deflation leads to an ischemia and reperfusion injury $(3,4,27,28)$. Hence, Pp would induce changes in podocyte morphology that were not seen in the present study. The glomerulus is considerably more sensitive to oxidative injuries than any other nephron segments (9). Nevertheless, no morphological or numerical changes in this structure were found after 3 hours of Pp at $8 \mathrm{mmHg}$. Possibly, only under higher intra-abdominal pressures, which do not simulate routine working pressures employed in humans, these alterations could be seen. 
An interesting study reported that renal blood flow did not decrease under 5 or $10 \mathrm{mmHg}$ intra-abdominal pressures in rats, but decreased under $15 \mathrm{mmHg}$ (29). This may explain previously findings with higher pressures used in this animal model.

As an ischemia and reperfusion injury, the Pp have been related to increased oxygen reactive species in the kidney (6) and different methods to diminish the oxidative stress were described in animal models, including melatonin (3), erythropoietin (5) pre-conditioning (28) and verapamil (30). Although the aforementioned authors have showed lipid peroxidation and protein oxidation in renal tissue, the intra-abdominal pressure used by these authors was always higher than $8 \mathrm{mmHg}$, which corresponds to more than $15 \mathrm{mmHg}$ in humans (7). In the present study, a prolonged $\mathrm{Pp}$ at $8 \mathrm{mmHg}$ did not induce oxidative stress in the renal tissue in rats.

In summary, this study demonstrated that even with a prolonged period, a Pp at $8 \mathrm{mmHg}$ did not induce oxidative stress or morphological changes in the rat kidney. Since more complex surgeries have been performed by laparoscopy and patients are submitted to more than 3 hours of Pp, a deep knowledge on possible renal damage caused by prolonged Pp could be established to determine when protective methods should be used.

\section{ABBREVIATIONS}

Pp: Pneumoperitoneum

HE: Hematoxylin and eosin

$\mathrm{CV}$ : Cortical volume

Vv[glom]: Glomerular volume density

VWGV: Volume weighted mean glomerular volume MDA: Malondialdehyde

\section{ACKNOWLEDGMENTS}

This study received grants from the National Council of Scientific and Technological Development, Foundation for Research Support of Rio de Janeiro and Coordination for the Improvement of Higher Education Personnel.

\section{CONFLICT OF INTEREST}

\author{
None declared.
}

\section{REFERENCES}

1. Demyttenaere S, Feldman LS, Fried GM: Effect of pneumoperitoneum on renal perfusion and function: a systematic review. Surg Endosc. 2007; 21: 152-60.

2. Bishara B, Karram T, Khatib S, Ramadan R, Schwartz H, Hoffman A, et al.: Impact of pneumoperitoneum on renal perfusion and excretory function: beneficial effects of nitroglycerine. Surg Endosc. 2009; 23: 568-76.

3. Cay A, Imamoglu M, Unsal MA, Aydin S, Alver A, Akyol A, et al.: Does anti-oxidant prophylaxis with melatonin prevent adverse outcomes related to increased oxidative stress caused by laparoscopy in experimental rat model? J Surg Res. 2006; 135: 2-8.

4. Yilmaz S, Koken T, Tokyol C, Kahraman A, Akbulut G, Serteser $\mathrm{M}$, et al.: Can preconditioning reduce laparoscopyinduced tissue injury? Surg Endosc. 2003; 17: 819-24.

5. Ates E, Yilmaz S, Ihtiyar E, Yasar B, Karahuseyinoglu E: Preconditioning-like amelioration of erythropoietin against laparoscopy-induced oxidative injury. Surg Endosc. 2006; 20: 815-9.

6. Akbulut G, Polat C, Aktepe F, Yilmaz S, Kahraman A, Serteser $\mathrm{M}$, et al.: The oxidative effect of prolonged $\mathrm{CO} 2$ pneumoperitoneum on renal tissue of rats. Surg Endosc. 2004; 18: 1384-8.

7. Avital S, Itah R, Szomstein S, Rosenthal R, Inbar R, Sckornik Y, et al.: Correlation of $\mathrm{CO} 2$ pneumoperitoneal pressures between rodents and humans. Surg Endosc. 2009; 23: 50-4.

8. Scherle W: A simple method for volumetry of organs in quantitative stereology. Mikroskopie. 1970; 26: 57-60.

9. Aguila MB, Pinheiro AR, Aquino JC, Gomes AP, Mandarimde-Lacerda CA: Different edible oil beneficial effects (canola oil, fish oil, palm oil, olive oil, and soybean oil) on spontaneously hypertensive rat glomerular enlargement and glomeruli number. Prostaglandins Other Lipid Mediat. 2005; 76: 74-85.

10. de Souza DB, de Oliveira LL, da Cruz MC, Abílio EJ, Costa WS, Pereira-Sampaio MA, et al.: Laparoscopic partial nephrectomy under warm ischemia reduces the glomerular density in a pig model. J Endourol. 2012; 26: 706-10.

11. Gundersen HJ, Jensen EB: Stereological estimation of the volume-weighted mean volume of arbitrary particles observed on random sections. J Microsc. 1985; 138: 127-42. 
12. Benchimol de Souza D, Silva D, Marinho Costa Silva C, Barcellos Sampaio FJ, Silva Costa W, Martins Cortez C: Effects of immobilization stress on kidneys of Wistar male rats: a morphometrical and stereological analysis. Kidney Blood Press Res. 2011; 34: 424-9.

13. Benchimol M: Mitosis in Giardia lamblia: multiple modes of cytokinesis. Protist. 2004; 155: 33-44.

14. Asanuma K, Yanagida-Asanuma E, Takagi M, Kodama F, Tomino Y: The role of podocytes in proteinuria. Nephrology (Carlton). 2007; 12: S15-20.

15. Draper $\mathrm{HH}$, Hadley $\mathrm{M}$ : Malondialdehyde determination as index of lipid peroxidation. Methods Enzymol. 1990; 186: 421-31.

16. Levine RL, Garland D, Oliver CN, Amici A, Climent I, Lenz $A G$, et al.: Determination of carbonyl content in oxidatively modified proteins. Methods Enzymol. 1990; 186: 464-78.

17. Lowry $\mathrm{OH}$, Rosebrough NJ, Farr AL, Randall RJ: Protein measurement with the Folin phenol reagent. J Biol Chem. 1951; 193: 265-75.

18. Berguer R, Cornelius T, Dalton M: The optimum pneumoperitoneum pressure for laparoscopic surgery in the rat model. A detailed cardiorespiratory study. Surg Endosc. 1997; 11: 915-8.

19. Lind MY, Hazebroek EJ, Bajema IM, Bonthuis F, Hop WC, de Bruin RW, et al.: Effect of prolonged warm ischemia and pneumoperitoneum on renal function in a rat syngeneic kidney transplantation model. Surg Endosc. 2006; 20: 1113-8.

20. Santos LS, Tambara Filho R, da Figueiredo TM, Cravo G: Effects of the pneumoperitoneum in rats submitted to a unilateral nephrectomy: morphologic and functional study on the remnant kidney. Acta Cir Bras. 2005; 20: 195-9.

21. Hazebroek EJ, de Bruin RW, Bouvy ND, Marquet RL, Bonthuis $\mathrm{F}$, Bajema IM, et al.: Long-term impact of pneumoperitoneum used for laparoscopic donor nephrectomy on renal function and histomorphology in donor and recipient rats. Ann Surg. 2003; 237: 351-7.

22. Hazebroek EJ, de Bruin RW, Bouvy ND, van Duikeren S, Bonthuis F, Marquet RL, et al.: Short-term impact of carbon dioxide, helium, and gasless laparoscopic donor nephrectomy on renal function and histomorphology in donor and recipient. Surg Endosc. 2002; 16: 245-51.
23. Mandarim-de-Lacerda CA, Fernandes-Santos C, Aguila MB Image analysis and quantitative morphology. Methods Mol Biol. 2010; 611: 211-25.

24. Khoury W, Jakowlev K, Fein A, Orenstein $H$, Nakache R, Weinbroum AA: Renal apoptosis following carbon dioxide pneumoperitoneum in a rat model. J Urol. 2008; 180: 1554-8.

25. Khoury W, Weinbroum AA: Oxidants as important determinants of renal apoptosis during pneumoperitoneum: a study in an isolated perfused rat kidney model. Surg Endosc. 2012; 26: 1417-24.

26. Wagner MC, Rhodes G, Wang E, Pruthi V, Arif E, Saleem $M A$, et al.: Ischemic injury to kidney induces glomerular podocyte effacement and dissociation of slit diaphragm proteins Neph1 and Z0-1. J Biol Chem. 2008; 283: 3557989.

27. Bickel A, Drobot A, Aviram M, Eitan A: Validation and reduction of the oxidative stress following laparoscopic operations: a prospective randomized controlled study. Ann Surg. 2007; 246: 31-5.

28. Arioz DT, Polat C, Tokyol C, Kakraman A, Yilmaz S, Demirel $\mathrm{R}$, et al.: What should be the ideal time for ischemic preconditioning in a laparoscopic rat model? J Laparoendosc Adv Surg Tech A. 2009; 19: 141-7.

29. Wiesenthal JD, Fazio LM, Perks AE, Blew BD, Mazer D, Hare $G$, et al:: Effect of pneumoperitoneum on renal tissue oxygenation and blood flow in a rat model. Urology. 2011; 77: 1508. e9-15.

30. Demirbas M, Guler C, Samli M, Köken T, Dincel C, Polat C: The effect of verapamil on the prevention of ischemia/reperfusion injury in the experimental retroperitoneoscopic donor nephrectomy model. Surg Endosc. 2004; 18: 1272-5.

\section{Correspondence address} Dr. Diogo B. de Souza

Urogenital Research Unit - UERJ Av. 28 de Setembro, 87, Fundos, Vila Isabel Rio de Janeiro, RJ, 20551-030, Brazil Telephone: + 5521 2868-8399 E-mail: diogobenchimol@gmail.com 